\title{
Methodological Problems in Determining the Basic Features of the Sample Set Controlling the Activities of the Enterprise
}

\author{
Tatyana N. Shatalova \\ Marina V. Chebykina \\ Tatyana V. Zhirnova
}

Elena Yu. Bobkova

Samara Institute of Plekhanov Russian University of Economics
Email: vica3@ya.ru

\section{Doi:10.5901/mjss.2015.v6n3s4p261}

\section{Abstract}

\begin{abstract}
This article examines the transformation of initial point of concept of "potential" in the dynamic process from the standpoint of dialectical aspect. Disclosed the essential characteristics of scientific concept of "potential", substantiated methodological approaches in the management of contact with the effective direction of the research category of "resource potential"; revealed the dynamic susceptibility as a key feature of the sample set of resources. The study is based on a comprehensive, integrated methodology for studying the problem of combining the basic tools and resource efficient approaches. An effective approach supposes principal settings and is treated as an economic entity's ability to use resources in the production process, the factors of production. This approach reflects the administrative aspect in the study of the economic category of the resource potential. Resource-based approach integrated with a targeted approach, involves the use of aggregate resources available entity. In identifying a key feature sample set of resources, the authors highlighted immanent and transcendent property of resources. Immanent property resources manifests in their ability to objectively, and comprehensively interact interconnected within the material conditions of the resource potential. Transcendental resources in its subjective form the aggregate sample of organizational conditions of the resource potential. The authors consider the category of "resource potential» as the material condition for the qualitative reproduction of its basic structural elements of a complex, and dynamically interacting with the modalities for the purpose of stable operation of enterprise in market conditions.
\end{abstract}

Keywords: resource potential elements, immanent resources, transcendental resources, controlling.

\section{Introduction}

The effectiveness of any socio-economic system, the solution of many problems of social development in reforming the economy, which is directly linked to the extensive, detailed assessment procedure to mobilize resources and, in particular, the results of human activity. Moreover, it is important to note that the analysis of the impact of the production system depends on two interrelated positions - objective and subjective. Objective reflects the possibility of the system itself and subjective position characterizes a person's ability to use these features. Thus, the effect of the current system determined by the degree of utilization of its total capacity, and effectiveness is dependent on the value of the use of existing capacity. Therefore, before proceeding to the definition of the resource potential, we consider it important to stay on clarifying the concept of potential.

\section{Methods}

In the research used an integrated methodological approach to the problem of combining the basic tools and resource efficient approaches. Resource-based approach involves the complex of the available resources of an economic entity, already in her integrational orientation finds purpose - the choice of resources; the linkage between resources, i.e. resource-based approach does not exist without a targeted approach. Productive approach, as well as at the stage of formation of resource potential, and at the stage of its use, the intended target setting (that's a choice of key resources, and identifying the most appropriate forms of pooling resources, and identifying opportunities rational and efficient use of resources, etc. ). Same effective approach that treated as an opportunity, the ability of the economic entity involved in the 
manufacturing process of resources, factors of production, largely reflects the administrative aspect in the study of economic category of the resource potential. Thus, efficient approach takes into account the total resources, and all the factors of production, which can ensure the effective functioning of the system.

\section{The Main Part}

Origins of ontological research subject area the term "capacity" is its etymological meaning. Therefore, translated from Latin, the term "potential" means the power, the power of possibility. It should be noted that many modern industry science took knowledge of the term "capacity" of the physics- energy state of the object, its tension (Shatalova, 2014). So, in biology capacity is viewed as a physical-chemical energy of biological modifications (Chebykina \& Bobkova 2014); in sociology - the energy of the individual, which is the starting point of the possible energy reaction of another subject (Chebykina \& Bobkova, 2013); in the social sciences - as a source (nat. pulse), the use of fragmentary sections of scientific knowledge to solve any problems in the field of public thinking (Shatalova \& Zhirnova, 2014). However, the original definition of this notion should attributed to the philosophy of Aristotle, who considered the Genesis as a synthesis of matter and form. Matter he treats as a possibility of being (or "potency", in the sense of ability to form). The form treated as an "Act" of this ability (ability). Unification of form and matter gives the Act. If explore an act by the part of the form, in the philosophy of Aristotle, it would be "entelechy" (i.e. inner strength, a source of potential enclosing the chain and the result). If explore the Act by matter, it will be a mixture of potency and act. Philosophical aspect of scientific categories "capacity" has allowed many researchers to describe the potential of economy uncertain, not detailed, without possible features. Transformed into actual opportunities they can only result - the action (process). We consider that the process approach to the definition of "capacity" significantly cuts back its essential characteristics. Here, in our opinion, should enter into force on the dialectical principle of universal interconnection (the interaction between matter and form). The substantiation of this position we find in Aristotle himself in the developed by them the concepts of dynamism to the purposes, for which it, revealing form as the main reason for existence, isolated (it classified) reasons (elements of mechanism) the causing changes from the opportunity to the reality: formal - essence of thing; material - substratum (structure) of thing; acting - that which sets in motion (is revealed initial moment to the process, i.e. prime movers); purposeful - aims of the perfect actions. In figure 1 authors presented the diagram of the transformation of the initial moment of concept "potential" into the dynamic action: dialectical aspect.

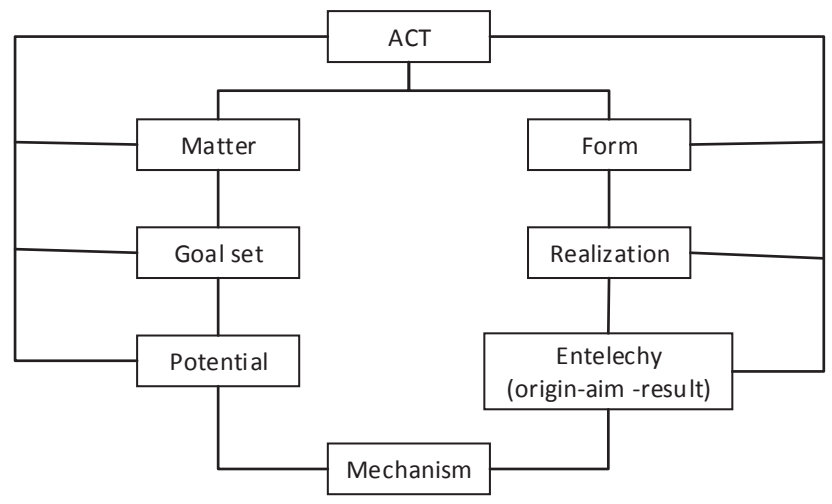

Figure 1. Transformation of the initial point of the concept of "potential" in a dynamic process: the dialectical aspect

All of above allow us to consider the term "potential", as a starting point (source) process; secondary as a dynamic process of achieving the goals. In the first case, the essential characteristics of the concept of "potential" is defined formal reasons of possible changes (sources, targets). In the second case, the essential characteristics of the concept of "potential" is determined directly by a dynamic process (mechanism) transition opportunities into reality; implementation of targets in the results (Table 1). 
Table 1. The essential characteristic of the scientific concept of "potential"

\begin{tabular}{|l|l|l|}
\hline Concept definition & The essential characteristic of the concept & In relation to the concept "resource potential" \\
\hline $\begin{array}{l}\text { Potential as a material condition, as } \\
\text { a starting point in the process. }\end{array}$ & $\begin{array}{l}\text { 1) Defined formal reasons of possible changes: } \\
\text { sources and targets. }\end{array}$ & $\begin{array}{l}\text { 1) Determined by the structure-forming elements of } \\
\text { the resource potential (sources) depending on the } \\
\text { target system settings. }\end{array}$ \\
\hline $\begin{array}{l}\text { Potential as a dynamic process to } \\
\text { achieve the goals. }\end{array}$ & $\begin{array}{l}\text { 2) Identifies specific dynamic processes } \\
\text { (mechanisms) transition opportunities into reality; } \\
\text { implementation of targets in the result. }\end{array}$ & $\begin{array}{l}\text { 2) Defined by an effective mechanism for managing } \\
\text { resource potential. }\end{array}$ \\
\hline
\end{tabular}

Data from Tabel 1 and Figure 1 allow justify theoretically system-process approach to the definition of the scientific term "potential". This approach can formulated as identifying the elements of the original component of the potential that have systemic effects on the dynamic processes of transition opportunities into reality. For further clarify the category of resource potential were analyzed existing research areas of his research in the economics literature, see. Tabel 2. (Ashmarina \& Sorochkin, 2012; Chebykina \& Bobkova, 2014; Chebykina \& Bobkova, 2014; Shatalova, 2014; Tushavin, 2014; Shatalova, Chebykina, Zhirnova \& Bobkova, 2014 \& Semenova, Smirnova \& Tushavin, 2014).

Tabel 2. Approximate classification definitions of resource potential on basic scientific research approaches

\begin{tabular}{|c|c|}
\hline Scientific approaches & The definition of resource potential \\
\hline \multirow{8}{*}{$\begin{array}{l}\text { Resource-based approach: an ordered set of resources. } \\
\text { Was quantified value of individual resources, their } \\
\text { quality characteristics. If we investigate, only a collection } \\
\text { of resources, their interaction and influence on each } \\
\text { other is not considered. If we study the system (ordered) } \\
\text { set of resources, it is necessary the introduction of } \\
\text { certain indicators that will clarify this system. }\end{array}$} & $\begin{array}{l}\text { - the totality of available resources, coupled with each other, the use of which } \\
\text { allows to achieve the economic effect }\end{array}$ \\
\hline & $\begin{array}{l}\text { - quantity and quality of resources at the disposal of one or another economic } \\
\text { system }\end{array}$ \\
\hline & - generalized, collective characteristics of resources \\
\hline & $\begin{array}{l}\text { - set of resources without real relationships prevailing in the production } \\
\text { process }\end{array}$ \\
\hline & - the collection of all funds, stocks, their sources and reserves \\
\hline & $\begin{array}{l}\text { - system resources used by the complex, i.e., provides for the } \\
\text { interchangeability of resources, and used in social production }\end{array}$ \\
\hline & $\begin{array}{l}\text { - includes human resources and staff organization, production resources, } \\
\text { material resources }\end{array}$ \\
\hline & - resource actual (real) and organizational factors of production \\
\hline \multirow{9}{*}{$\begin{array}{l}\text { Effective approach: the potential considered from the } \\
\text { viewpoint of the economic entity involved in the } \\
\text { manufacturing process of actual resources, factors of } \\
\text { production to produce a certain amount of wealth. } \\
\text { The result in this case is a "platform" to assess the } \\
\text { resource potential as a whole, and its building blocks }\end{array}$} & $\begin{array}{l}\text { - the ability of the economic system to develop, process resources to meet } \\
\text { social needs }\end{array}$ \\
\hline & $\begin{array}{l}\text { - the ratio of the benefits of the use of resources at a certain point in the } \\
\text { branch system to the value of the resource (rate of return of resources) }\end{array}$ \\
\hline & $\begin{array}{l}\text { - co-operating set of resources that have the ability to produce a certain } \\
\text { amount of product }\end{array}$ \\
\hline & $\begin{array}{l}\text { - the dynamics of the market value of the test as an integral indicator of the } \\
\text { effectiveness of the company }\end{array}$ \\
\hline & - value of a business, as reflected in the balance sheet \\
\hline & - macroeconomic category, ie total capacity of sectors of the economy \\
\hline & $\begin{array}{l}\text { - level of economic efficiency, which depends on the variety of resource } \\
\text { factors }\end{array}$ \\
\hline & $\begin{array}{l}\text { - Sources improve efficiency - reducing the labor intensity, material } \\
\text { consumption, capital intensity and capital intensity of production }\end{array}$ \\
\hline & $\begin{array}{l}\text { - set of labor, natural and material costs, which are determined by the } \\
\text { quantity, quality and internal structure of each resource. }\end{array}$ \\
\hline \multirow{7}{*}{$\begin{array}{l}\text { Targeted approach: resource potential considered in } \\
\text { terms of the ability of the economic entity to identify, } \\
\text { organize, implement and adjust the target setting to } \\
\text { achieve the best possible results, using the available } \\
\text { resources. }\end{array}$} & - Resource capabilities of the system for different purposes \\
\hline & $\begin{array}{l}\text { - The ability of the system, in view of account of the total resources and } \\
\text { reserves, to achieve strategic objectives and operate stably }\end{array}$ \\
\hline & $\begin{array}{l}\text { - resource potential is more consistent with the objectives of tactical rather } \\
\text { than strategic management }\end{array}$ \\
\hline & - set of natural and economic resources involved in achieving the objective \\
\hline & $\begin{array}{l}\text { - the intended use of each element of the resource potential in the production } \\
\text { process }\end{array}$ \\
\hline & $\begin{array}{l}\text { - the use of structural elements of the potential for the realization of social } \\
\text { and economic goals }\end{array}$ \\
\hline & - implementation of targets of each element in the structure of the potential \\
\hline
\end{tabular}


Results of the analysis allowed establishing that they are more or less in common both among themselves and with the methodological approaches in the field of management.

Having summarized in Table 2 the main research areas in the study of economic category of resource potential (resource-based approach, effective approach targeted approach), we can say that they are more or less in common, both among themselves and with the methodological approaches in the field of management. Thus, the resource-based approach that involves the totality of the available resources of an economic entity, in the direction of their integration is the goal - the choice of resources; the linkage between resources, i.e., resource-based approach does not exist without a targeted approach. Effective approach, as well as at the stage of resource potential, and at the stage of its use, the intended target setting (this is, and key resources, and identifying the most appropriate forms of pooling resources, and identifying opportunities rational and efficient use of resources, etc. ). The very same effective approach that treated as an opportunity, the ability of the economic entity involved in the manufacturing process of resources, factors of production, largely reflects the administrative aspect in the study of economic category of the resource potential. Thus, efficient approach takes into account the total resources, and all the factors of production, which can ensure the efficient functioning of the system. Its essential characteristic manifested in such management practices as a system, process; comprehensive, economic, adaptive, situational (Table 3).

Table 3. Methodological approaches in the management of contact with the effective direction of research category resource potential

\begin{tabular}{|c|c|}
\hline Methodological approaches & Brief characteristics \\
\hline \multirow[t]{2}{*}{ Economical } & Determines the most cost-effective management of the organization. \\
\hline & $\begin{array}{l}\text { In effective approach manifests itself in determining the rational structure of the resource potential (i.e. } \\
\text { to reduce the proportion of the cost of the building blocks of capacity; to improve the efficiency of their } \\
\text { use). }\end{array}$ \\
\hline \multirow[t]{2}{*}{ Complex } & $\begin{array}{l}\text { Implies taking into account all the components of the control system - goals, objectives, operating } \\
\text { conditions, management strategy and development. }\end{array}$ \\
\hline & $\begin{array}{l}\text { In effective approach manifested in the quantitative assessments of the effectiveness of integrated } \\
\text { management resource potential of the system. }\end{array}$ \\
\hline \multirow[t]{2}{*}{ Adaptive } & $\begin{array}{l}\text { Involves the construction of (organization) of the mobile control system that, when changing internal } \\
\text { and external conditions, the flexibility to change and determine, in turn, operational adaptability to } \\
\text { business instability of the environment. }\end{array}$ \\
\hline & $\begin{array}{l}\text { In effective approach manifests itself in the modification of the building blocks of the resource potential, } \\
\text { production factors affecting its formation as a function of changes in the external and internal } \\
\text { conditions. }\end{array}$ \\
\hline \multirow[t]{2}{*}{ Process } & $\begin{array}{l}\text { Assumes control of the system considered as a series of interrelated activities (functions), each of } \\
\text { which in itself is a process }\end{array}$ \\
\hline & $\begin{array}{l}\text { In effective approach manifests itself in the target setting for the pooling of resources for optimum } \\
\text { utilization of the resource potential, which implies functional actions of managers to plan, organize } \\
\text { resource base of economic entity, as well as the implementation of the organizational and economic } \\
\text { processes efficient use of the resource potential. }\end{array}$ \\
\hline \multirow[t]{2}{*}{ Systematic } & $\begin{array}{l}\text { Suggests that considering the organization as a whole system, all of whose elements are } \\
\text { interconnected. Each indivisible (as part of the system) brings its own characteristics in the overall } \\
\text { system. Any system has inputs and outputs. }\end{array}$ \\
\hline & $\begin{array}{l}\text { In effective approach manifests itself in the target plants at the entrance of the system (identification of } \\
\text { the resource base of the subject), which in a functioning system can be taken as a result of (fact) and } \\
\text { results in the target output system (efficient use of the resource potential). }\end{array}$ \\
\hline \multirow[t]{2}{*}{ Situational } & $\begin{array}{l}\text { Implies taking into account specific situations, the conditions of the internal environment and the } \\
\text { external environment in which the system operates. This approach reflects the quality of the } \\
\text { organization's management system, that is, is a necessary component of the system approach. }\end{array}$ \\
\hline & $\begin{array}{l}\text { In effective approach manifested in the regrouping of the resource base, production factors influencing } \\
\text { the resource potential for the realization of the possibility of providing the maneuverability of the } \\
\text { system in a changing market environment. }\end{array}$ \\
\hline
\end{tabular}

Thus, identified systemic-process elements in the characterization of the notion of "potential", summarized research directions in the study of interpretation of the definition "resource potential", and allowed us to disclose the essential content of this category logical approach from the perspective directions of system and process research. As the resource potential, is a complex, multifaceted economic category, manifested and structural element and starting (starting) point for the development of other types of building, consider legitimate explore a category from the perspective of the social mode of production. 
Traditionally, public mode of production characterized by economic theory as a way of organizing social production, which in turn is defined as the unity and interaction of productive forces and relations. Production itself, as a process of social labor classified into phases: direct production; distribution; interchange; consumption. Material basis of the economy are productive forces. These include natural capabilities of society, the factors of production and resources capable of creating public goods and ensure the growth of labor productivity. (Algina\& Bodnar, 2011 \& Chebykina, Bobkova, 2014.). In economic theory, the productive forces are divided into two groups. The productive forces of the first sequence, which include primary (classical) factors of production - labor power, means of production, entrepreneurial abilities (Ashmarina \& Sorochkin, 2012; Chebykina \& Bobkova, 2014 \& Shatalova 2014).

With reference to the investigation of the resource potential, we consider them as legitimate determine actual resource conditions, as factors of production is, above all, the resources used in the production process and by certain conditions are creating goods and services. It should be noted that in the economic literature remains controversial question of inclusion in the first group of the productive forces of the actual condition of the resource of entrepreneurial skills. In the market conditions of economic management of enterprise, while have been increasing dynamism, as well as the flow of innovations in production processes and division of labor, particularly gets important the resource management, ensuring coordination linkages between different resource conditions in the effective functioning of the system. In this case, management resources rightfully belong to the group of the productive forces of the second order. The productive forces of the second order include a number of other factors (innovation, environmental, etc.), which indirectly effect on the results of the labor process. In the research of the resource potential of these factors, we will characterize as organizational conditions of the production. Ways of connection the productive forces of the first and second order in their totality defines (form) resource potential. Effective use of (consumption) resources - resource potential in the production process, we define as productive consumption, which can be a result of production or production potential. In research have considered consumers' production with defining qualitative content of consumption performance.

Consumer-production - a set of processes (organizational, social, technological, etc.) whereby which reproduces the social content of life (Ashmarina \& Sorochkin, 2012, Chebykina \& Bobkova, 2013). Quality content is manifests in new useful properties of the results of labor, namely, the use value of the product. Use value - a set of useful properties of the product, due to which it is able to satisfy any requirement of the person (Algina \& Bodnar, 2011; \& Shatalova, 2014). In the aspect of the research of this category, (that is not the purpose of our work), can be considered and multivariate sides of the impact of the economic potential, which can be shown, for example, in the productive capital, in the consumer capital, etc. If the result considered as a use value, then we can talk about the implementation of the principle: the production in order to satisfaction needs. Moreover, here become important industrial relations. Relations of production traditionally characterized as a set of economic relations between people, folding in the process of social production and social movement of the product from production to consumption (Ashmarina \& Sorochkin, 2012; \& Shatalova \& Zhirnova, 2014). They are divided into organizational and economic; socioeconomic; techno-economic. Economic-organizing relations reflect the form of organizational constraints (specialization, cooperation, concentration and centralization, organization of social production, management) accompanying joint activities of people in the process of production, distribution, exchange and consumption (Algina \& Bodnar, 2011; Chebykina \& Bobkova, 2014; Chebykina \& Bobkova, 2014, Shatalova \& Grachova, 2014; Chebukina, Shatalova, Jirnova \& Bobkova, 2013 \& Semenova, Smirnova \& Tushavin, 2014). Socioeconomic relationship - that is relationship between social groups, separate groups over use and disposal of the means of production. These relationships are defined with forms of ownership of the means of production (Ashmarina \& Sorochkin, 2012; Chebykina \& Bobkova, 2013, Shatalova \& Grachova, 2014). Techno-economic relations develop between people in the process of creation and use of objects of labor. They characterize the tangible nature of social production - the state of the art; level of technology, etc. Thus, at the stage of production of consumers' form of implementation of the productive forces are the relations of production. In addition, here, we believe that the economic potential is more pronounced in the prevailing inter-relations of production.

The economic potential that's primarily- economic capabilities of the system, which are determined by the level of development of productive forces, but are economically dependent on the level of development of industrial relations that arise between employees, teams, management personnel of the enterprise over the use of their ability to create a product. Relations of production, to the economic possibilities of the system (economic potential) can both encourage and slow the development of the productive forces (the resource potential) because either diminish incentives to work in economic entities, or increasing the incentive by multiplying.

Many scientists exploring the resource potential (which, together with production potential, as we noted above, is an integral part of the economic potential) based on the hierarchical structure of indicators approaching to the analysis of the influence of the dynamics of the effectiveness of the exploitation of certain types of resources in order to determine 
the contribution of a particular resource on changes in the total factor of efficiency.

Thus, the total number of scientists' textured performance expressed as the sum of the weighted average rate of growth of certain types of resource efficiency, where the weighting factors are the share of costs related resources in the total national economic cost (Ashmarina \& Sorochkin, 2012 \& Chebykina \& Bobkova, 2014). That is the basis for the calculations are taken by symbolic full national economic costs. Other researchers have proposed a method of expression of labor embodied labor (Algina \& Bodnar, 2011). The authors hold the view, according to which production is spent on living labor workers in this industry and the means of production, industrial production.

The means of production in turn are the result of human labor and associated costs of means of production in the previous stages of production. Materialized labor is taken into account in terms of value, and live - in person-hours or number of employees. In this regard, the problem of calculating the total cost of labor is reduced primarily to the isolation of homogeneous material costs and the cost of the recount of money in labor expression. In this case, different approaches are possible.

Application of these calculations in practice is not always possible due to the cumbersome calculations and lack of primary data. In addition, in the present conditions suitable valuation of the total cost.

By this line of reasoning, it can be summarized that the problem of relations between the basic elements of the economic potential of the enterprise can't have and constant shape, as the different stages of the production process change and driving forces (conditions) that determine the quality characteristics of all the components of the potential.

However, for many years in our country and in it's terms of reforming of the national economy, many companies have frozen the structure of the resource potential, and hence of the economic potential. It was connected with the unrealistic value of fixed assets, which in any ratio distorted and causes an imbalance full potential, which, of course, affects the functioning of the enterprise. At present, there was a dramatic change in the structure of the material factors. In addition, here it is advisable to carry out the analysis in terms of "fullness" components from the point of view of the economic potential of qualitative content. Fundamental (primary) as part of the economic potential are the resources (material factors).

We consider that just its effective use is correct and actual valuation of these factors with the new quality content will allow reasonably assessed as production potential and the economic potential of the enterprise.

We back the view of the authors, who believe that the occupancy of the economic potential of the enterprise quality content can be done through environmental factor (Semenova, Smirnova \& Tushavin, 2014). Environmental factors as well as the land is part of the economic potential, fully dependent on natural conditions and force majeure. This provision in the analysis of the economic potential of the company allows us to highlight the environmental factor as an essential condition for constant evaluation adjustment as labor, material and technical resources and evaluation of the potential of the company. Quality content through environmental factor determines and reveals certain relationship private performance of individual elements to each other, and hence the elements themselves. Based on the fact that the material factors of economic potential and their performance is diverse and valued by us, of course, in the valuation, then explore all the components of capital expedient in their entirety. Considered separately, each factor is necessary for the economic potential of its role in the creation of value of the product. In this case, once again emphasize that the resources in conjunction with the production activities of the enterprise reflect the efficiency of the production potential. Manufacturing same potential with income businesses reflects the economic potential of the enterprise.

\section{Conclusion}

Above author's methodological position research category of the resource potential in the broad sense of the word considered as a result of the development of the productive forces of society in the structure of economic potential, which in turn is largely dependents on the level of development of the relations of production, is logically justified. So, if connect the philosophical aspect of the economic content and capacity development from the perspective of the social process of production, the first part of the production process reflects the material side of his process (initial) - $t$. $E$. The productive forces. The second part of the process of social production reflects the relations of production, i.e., dynamic (target) motion (process) of the productive forces (the resource potential) for productive consumption (production potential) and then to use-production, as a result of the second order of the productive forces (the resource potential) at a better round of development, defining, eventually - use value. Figure 2. 


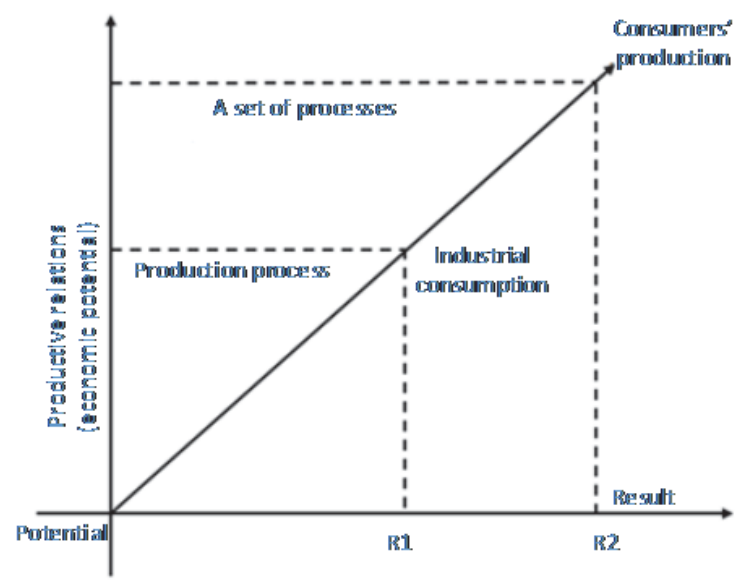

Figure 2. Economic transformation of resource potential in the structure of the social process of production

On the figure 2. impact of the first order (production potential) is designated as R1, and the impact of the second order (use value) - as R2. Should be noted that the authors believe that the resource potential is the "starting point", "momentum" to the formation of productive capacity and thus share these categories. The productive capacity of the enterprise reflects the efficiency of resource potential productive capacity of compositionally manifested in the production of the manufacturing process, which results in the output (Ashmarina \& Sorochkin, 2012; Chebykina \& Bobkova, 2014; Shatalova \& Zhirnova, 2014 \& Shatalova, Chebykina, Zhirnova \& Bobkova, 2014). From this perspective, can be regarded as the productive capacity of the actual possibility of an economic entity to produce (wealth). This ability of the enterprise depends on the quantitative and qualitative correlation of the resource base of enterprise and organizational conditions of its operation. Justifying the dynamic susceptibility as a key feature of the sample set of resources (see. Figure 3), the authors consider it necessary to divide them into immanent and transcendent resources.

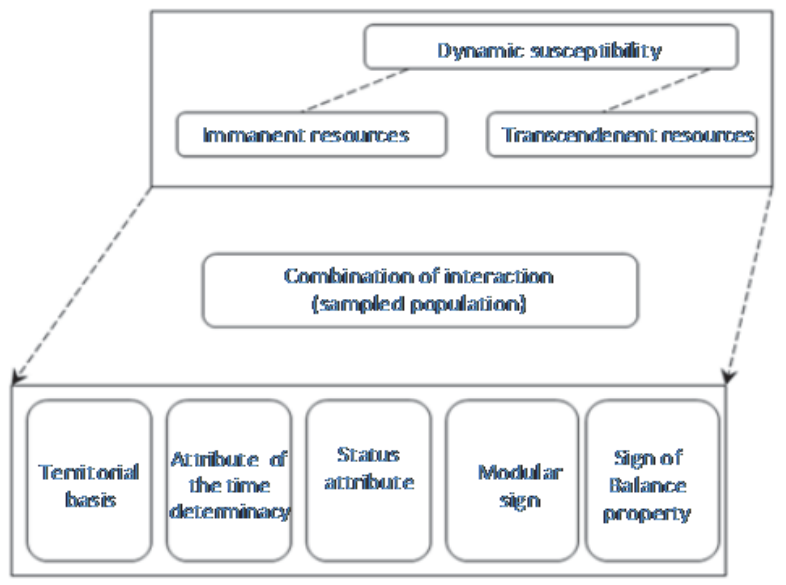

Figure 3. Dynamic susceptibility as a key feature of the sample set of resources

Immanent resources - resources that are directly involved in the process of production (labor, material and technical resources, land resources). Immanent property resources is manifested in their shaping, i.e. in an objective ability to interact in a complex and interconnected within the material conditions of the resource potential. Transcendental resources - the resources that are involved indirectly in the manufacturing process. Transcendental property resources is manifested in the fact that, firstly, they act as the subjective sources of coordinating and organizing the inherent quality resources. It should be noted that this property is functionally reflects the essence of the controlling activities of the facility, namely: focus on the efficiency of enterprises in the relatively long term - the philosophy of profitability; the formation of the organizational structure aimed at the achievement of strategic and operational objectives. Secondly, transcendental property resources act as subjective sources successful interaction inherent resources with the 
environment that ensures stable operation of the enterprise market. Transcendental resources in its subjective form the aggregate sample organizational conditions of the resource potential. All of the above allows us to specify the essential content of the concept of resource potential as a material condition for quality reproduction of its basic structural elements of a complex and dynamically interacting with the modalities for the purpose of stable operation of enterprise in market conditions.

\section{References}

Algina, M.V. \& Bodnar, V.A. 2011. The innovative potential of the economic system and its evaluation. Modern control technology, 1. pp. $15-22$.

Ashmarina, S.I. \& Sorochkin A.N. 2012. The resource component of the evaluation of information and knowledge potential of industrial enterprises. Vestnik of Samara University of Economics, 12. pp. 5-11.

Chebykina, M.V., Bobkova E.Yu. 2014. The Set Of Anti-Recessionary Measures Of The Energy Policy Of Industrial Enterprises In The Resource-Saving Sphere. In the world of scientific discoveries. 9.1 (57). pp. 542-551.

Chebykina, M.V. \& Bobkova E.Yu. 2014. Capitalization of resource factor in formation of enterprise economic potential. Yelm, WA, USA: Science Book Publishing House LLC. pp.185.

Chebykina, M.V. \& Bobkova E.Yu. 2013. The resource balance of the factors of production in the formation of the company's capital. Economics and entrepreneurship, 5. pp. 458-461.

Shatalova, T.N. \& Zhirnova T.V. 2014. System Of Industrial Enterprise Controlling: Problems And Prospects. Yelm, WA, USA, Science Book Publishing House LLC.

Shatalova, T.N. 2014. Process Approach In The Implementation Of The Strategic Objectives Of The Industrial Enterprise. Modern trends of strategic development of the enterprises: Proceedings of the International scientific and practical conference .Yelm, WA, USA. pp. $4-10$

Shatalova, T.N. \& Grachova E.S. 2014. Integration Of Transitive Economies Unions. Yelm, WA, USA. Science Book Publishing House LLC.

Tushavin, V. 2014. Axiomatically design projects as a tool to improve the quality. Modern trends of strategic development of the enterprises: Proceedings of the International scientific and practical conference. Yelm, WA, USA.: Science Book Publishing House. pp. 61-67.

Chebukina, M.V., Shatalova T.N., Jirnova T.V. \& Bobkova E.Y. 2013. Controlling as a Tool for Implementation of the System for the Enterprise Resource Potential Management in its Capitalized Form. World Applied Sciences Journal 27 (4): pp. $444-447$.

Shatalova, T.N., Chebykina M.V., Zhirnova T.V. \& Bobkova E.Yu. 2014. Base of Instruments for Managing Energy Resources in Monitoring Activity of Industrial Enterprises.Advances in Environmental Biology, 8(7) May 2014. pp. 2372-2376.

Semenova, E. G., Smirnova M. S. \& Tushavin V. A. 2014. Decision making support system in multi-objective issues of quality management in the field of information technology // Research Journal of Applied Sciences. Volume 9, Issue 12, 2014, pp 10781081. 